\title{
Lipophilic Components of Different Therapeutic Mud Species
}

\author{
ERSIN ODABASI, M.D., ${ }^{1}$ HUSAMETTIN GUL, M.D., Ph.D., ${ }^{2}$ ENIS MACIT, M.Sc., ${ }^{2}$ \\ MUSTAFA TURAN, M.D., ${ }^{1}$ and OGUZHAN YILDIZ M.D., Ph.D. ${ }^{3}$
}

\begin{abstract}
Objective: Mud, which contains organic and mineral ingredients, is used for the treatment of several degenerative diseases. It has been proposed that beneficial effects of mud are not only related to its local thermal effects, but also to its chemical components. Unlike hydrophilic components, the lipophilic components of the mud extract have not been described precisely thus far. Thus, we aimed to determine the lipophilic components of the different mud species.

Methods: Three different mud species (e.g., krenogen, tone, and fango) were analyzed by using gas chromatography-mass spectrometry (GC-MS).

Results: There were organic substances with fatty-acid structures found in the structure of mud. Torf mud species contain the most compounds. The compounds of three mud species differ from each other.

Conclusions: The chemical structure of mud does not only contain hydrophilic organic substances, such as humic, fulmic, and ulmic acids, but also low-molecular-weighted organic substances composed of fatty acids in the majority. Moreover, it would not be appropriate to explain mud with a single term, since it has different chemical structures and a new classification of the mud species is required.
\end{abstract}

\section{INTRODUCTION}

B alneotherapy, including mud therapy of rheumatic diseases and other musculoskeletal conditions, is one of the oldest forms of natural therapies. ${ }^{1}$ This ancient method of therapy is still widely used in central Europe, and is experiencing a rejuvenation in many countries, including the United States and Canada, where it is hardly known by mainstream medicine representatives.

Mud therapy, applied to the whole body, alone, or in combination with other modalities of balneotherapy, has been shown to improve symptoms of rheumatoid arthritis, psoriatic arthritis, fibromyalgia, and osteoarthritis. ${ }^{2}$ The beneficial effect of mud treatment has been often ascribed to the heat alone, but several studies showed that a specific action should also be considered. It has been reported that aqueous pharmacologically active and water-soluble (hydrophilic) sub- stances of mud extracts could permeate human skin in quantities that are sufficient to cause biologic effects. ${ }^{3}$ Although gallic, vanilic, humic, and protocatechic acid derivatives were shown in the aqueous mud extract, fulmic and ulmic acid derivatives were found predominantly and considered as responsible substances of chemical activity of the mud. ${ }^{4}$ However, it is still not clear which elements or organic substrates are essential and what is the ideal concentration of each element in order to attain an optimal response to treatment. We think that chemical effects of the mud species could be attributed not only to hydrophilic components of the thermal mud pack, but also lipophilic components may contribute to this effect. To our knowledge, unlike hydrophilic components, the lipophilic components of the mud extract have not been described precisely thus far. Thus, we aimed to determine the lipophilic components of mud, using gas chromatography-mass spectrometry (GC/MS).

Departments of ${ }^{1}$ Medical Ecology and Hydroclimatology, ${ }^{2}$ Analytical Toxicology, and ${ }^{3}$ Pharmacology, Gulhane School of Medicine, Ankara, Turkey. 
Table 1. Lipophilic Components of Krenogen Mud

Lipophilic components

Heptadecanoic acid

Hexadecanoic acid

Octadecanoic acid

9-otadecanoic acid

Dodecanoic acid

Tetracosenoic acid (margaric acid)

(palmitic acid)

(stearic acid)

(oleic acid)

(lauric acid)

(nervonic acid)

\section{MATERIALS AND METHODS}

\section{Mud species and definition}

The three mud species used in this study were defined according to the classification done by the German Spa Association..$^{5}$ (The term peloid was used instead of mud in this classification). Although there were many subgroups under this classification, main groups, including mud, were used for definitions instead of subgroups. Based on this, torf mud occurs owing to the rotting of plantal materials under a stillwater environment. The rotting layers gradually moving toward the deep layer of earth, where the oxygen supply cuts off, are then subjected to chemical processes (i.e., humification processes). Krenogen mud is composed of so-called substances, which occur during long-term contacts with thermal waters. The term krenogen mud, used in this study, is made of mud containing thermal water with sulfide ingredient. Fango mud does not depend on the existence of water, since it is a dry residual product of solid rock, which is insoluble in water. Mud species used in this study were obtained from the Denizli and Eskisehir regions in Turkey.

\section{Methods}

Five (5) g of three different mud species (krenogen, tone, and torf) were extracted separately with $10 \mathrm{~mL}$ of acetonitrile and $10 \mathrm{~mL}$ of chloroform and then centrifuged (Nuve, Istanbul, Turkey) for 5 minutes at $3000 \times \mathrm{g}$. The supernatant was obtained and evaporated to dryness under nitrogen in a water bath at $40^{\circ} \mathrm{C}$ and then dissolved in $200 \mu \mathrm{L}$ of methanol, from which $2 \mu \mathrm{L}$ was injected into GC-MS.

Analysis of the extracts was performed by using a GCMS-QP5050 (Shimadzu, Kyoto, Japan), equipped with a

Table 2. Lipophilic Components of Fango Mud

\begin{tabular}{ll}
\hline & \multicolumn{2}{c}{ Lipophilic components } \\
\hline Tetracosenoic acid & (myristic acid) \\
9-otadecanoic acid & (oleic acid) \\
Hexadecanoic acid & (palmitic acid) \\
Dodecanoic acid & (lauric acid) \\
Eicosanoic acid & (arachidic acid) \\
\hline
\end{tabular}

Table 3. Lipophilic Components of Torf Mud

\begin{tabular}{ll}
\hline \multicolumn{2}{c}{ Lipophilic components } \\
\hline Hexadecanoic acid & (palmitic acid) \\
9,12-octadecadienoic acid & (linoleic acid) \\
9-otadecanoic acid & (oleic acid) \\
Octadecanoic acid & (stearic acid) \\
Dodecanoic acid & (lauric acid) \\
Tetracosenoic acid & (myristic acid) \\
Phthalic acid & \\
2-monostearin & \\
1-monoarchidin & \\
Tryptamine & \\
$\alpha$-tocopherol & \\
\hline
\end{tabular}

capillary DB-5 $30 \mathrm{~m} \times 0.25 \mathrm{~mm} \times 0.25 \mu \mathrm{m}$ column $(\mathrm{J} \&$ W Scientific Inc., Folsom, CA) in the electron impact (EI) mode. The analyses of extracts were performed qualitatively in the full-scan mode in the range of $35-550(\mathrm{~m} / \mathrm{z})$ with 70 $\mathrm{eV}$. The temperature program was in the range of $65-300^{\circ} \mathrm{C}$ $\left(80^{\circ} \mathrm{C}\right.$ held for 3 minutes before a temperature ramp at $20^{\circ} \mathrm{C} / \mathrm{min}$ to $300^{\circ} \mathrm{C}$ and held at $300^{\circ} \mathrm{C}$ for 10 minutes).

\section{RESULTS}

We analyzed the compounds of three different types of mud species, using GC-MS. The compounds were shown in Tables 1-3 for krenogen mud, fango mud, and torf mud, respectively. Torf species contain the most compounds. The contents of three mud species differ from each other (Table 4).

\section{DISCUSSION}

In this study, many organic substances, with molecular weights lower than $1000 \mathrm{Da}$, mainly composed of fatty

Table 4. Differences Between the Three Mud Species

\begin{tabular}{lccc}
\hline Lipophilic components & Torf & Krenogen & Fango \\
\hline Palmitic acid & + & + & + \\
Linoleic acid & + & & \\
Oleic acid & + & + & + \\
Stearic acid & + & + & + \\
Lauric acid & + & + & + \\
Myristic acid acid & + & & \\
Phthalic acid & + & & + \\
Margaric acid & & & \\
Arachidic acid & & & \\
Nervonic acid & + & & \\
1-monarachidin acid & + & & \\
2-monostearin acid & + & & \\
$\alpha$-tocopherol & + & & \\
Tryptamine & + & & \\
\hline
\end{tabular}


acids, were found in the chemical structure of different mud species by using the GC-MS method. In addition, we observed that the contents of mud species differ from each other. The mud species, containing the most organic substances with a fatty acid structure, was found to be torf mud.

Our study demonstrates that the chemical ingredients of the mud species differ from each other for the first time. In addition, the effects of these substances on osteoarthritis, rheumatoid arthritis, and psoriasis have not been discussed in other papers. Nevertheless, it is not possible to show clearly the mechanism of the effect of the mud treatment. It has been claimed that these benefits result from the combination of chemical and thermal effects. ${ }^{6}$ The clear understanding of thermal effects is, unfortunately, not valid for that of chemical effect. There is also no consensus about the substances, which are responsible for the chemical effects.

In osteoarthritis, rheumatoid arthritis, psoriasis, and fibromyalgia studies, where Dead sea-Israel mud is used as a mudpack, it has been expressed that beneficial effects may occur not only from thermal effects, but also from chemical effects. It has also been pointed out that minerals such as bromine, rubidium, calcium, and zinc were assumed to play a role on chemical effects. ${ }^{7-12}$

Further, it was shown that the therapeutic activity of mature thermal mud is owing to an anti-inflammatory compound, sulphoglycolipid, which is produced by colonizing microorganisms during the maturation process. ${ }^{13}$ However, Beer et al. reported that water-soluble compounds of fulvic and ulmic acids were found to have a stimulatory response on the contractile activity of smooth muscle tissue. ${ }^{3}$ In addition to these two compounds, the impacts of humic acid derivatives as a component of the chemical effects were proposed by the same researchers. ${ }^{14}$ It was also assumed that gallic, vanilic, and protocatechic acid derivatives might play a role on the chemical effects of mud. ${ }^{4}$ In conclusion, no other substances were reported regarding their impacts on the chemical structure of mud, as mentioned above, except minerals, humic, gallic, vanilic, and protocatechic acid derivatives, and sulphoglycolipid compounds.

On the other hand, our study is unique in showing the different chemical compounds among mud species. We believe that these differences may be related to differences in the mechanisms of the formation of mud species. This may also explain the existence of much more organic compounds in torf mud, since this group of mud has been more exposed to organic formation, compared to other mud species, considering the duration of mud formation.

It is well known that the composition of mud in general is very complex and it may differ, depending on the mud source. Moreover, the quality and composition of mud may depend on various factors, such as the place of origin, the primary types of the plant origins, and a whole spectrum of environmental factors. ${ }^{3,5}$ However, we do not know how the differences in chemical compounds existing in mud species may affect the quality of balneologic therapy. Our study also shows that the English terminology used in this treatment, such as mudpack, mud treatment, mud therapy, and so forth, are not enough to explain the differences within chemical structures. In other words, these substances, having different formation conditions, ${ }^{15}$ containing different ratios of organic and inorganic minerals, ${ }^{16}$ and having different heat and water capacities, ${ }^{17}$ were explained by one mud definition without considering the above-mentioned differences. Thus, we believe that the terminology used for mud treatment should be reconsidered, based on these summarized differences.

On the other hand, it is not possible to answer clearly the role of fatty acid-structured organic substances, ${ }^{18-20}$ which were consumed within daily nutrition, on the chemical effects during mud therapy through skin.

\section{CONCLUSIONS}

In conclusion, the chemical structure of mud does not only contain hydrophilic substances, such as humic, fulmic, and ulmic acids, but also fatty acid-structured organic substances with lower molecular weights. In order to find the impact of these substances-alone or in combination-on the chemical effects of mud, further studies are required. Moreover, instead of using one single mud term for substances that have different chemical structures, a more detailed definition and/or classification should be used.

\section{REFERENCES}

1. Donmez A, Karagulle MZ, Tercan N, Dinler M, Issever H, Karagulle M, Turan M. SPA therapy in fibromyalgia: A randomised, controlled clinic study. Rheumatol Int 2005;26: 168-172.

2. Codish S, Abu-Shakra M, Flusser D, Friger M, Sukenik S. Mud compress therapy for the hands of patients with rheumatoid arthritis. Rheumatol Int 2005;25:49-54.

3. Beer AM, Junginger HE, Lukanov J, Sagorchev P. Evaluation of the permeation of peat substances through human skin in vitro. Int J Pharm. 2003;6:169-75.

4. Beer AM, Lukanov J, Sagorchev P. Isolation of biologically active fractions from the water-soluble components of fulvic and ulmic acids from peat. Phytomedicine 2002;9:653-666.

5. Deutscher Heilbaderverband e.V. BegriffsbestimmungenQualitätsstandards für die Prädikatisierung von Kurorten. [German Spa Association. Draft Quality Standards for Spa Medicine Practice]. Bonn: Erholungsorten und Heilbrunnen, 2005.

6. Matz H, Orian E, Wolf R. Balneotherapy in dermatology. Dermatol Ther 2003;16:132-140.

7. Wigler I, Elkayam O, Paran D, Yaron M. Spa therapy for gonarthrosis: A prospective study. Rheumatol Int 1995;15:65-68.

8. Sukenik S, Flusser D, Abu-Shakra M. The role of spa therapy in various rheumatic diseases. Rheum Dis Clin North Am 1999;25:883-897. 
9. Sukenik S, Buskila D, Neumann A, et al. Sulphur bath and mudpack treatment for rheumatoid arthritis at the Dead Sea area. Ann Rheum Dis 1990;49:99-102.

10. Karagulle Z, Donmez A. Balneotherapy for fibromyalgia at the Dead Sea. Rheumatol Int 2002;21:210-211.

11. Sukenik S, Flusser D, Codish S, Abu-Shakra M. Balneotherapy at the Dead Sea area for knee osteoarthritis. Isr Med Assoc J 1999;1:83-85.

12. Sukenik S, Baradin R, Codish S, Neumann L, Flusser D, AbuShakra M, Buskila D. Balneotherapy at the Dead Sea area for patients with psoriatic arthritis and concomitant fibromyalgia. Isr Med Assoc J 2001;3:147-150.

13. Tolomio C, Ceschi-Berrini C, Moschin E, Galzigna L. Colonization by diatoms and antirheumatic activity of thermal mud. Cell Biochem Funct 1999;17:29-33.

14. Beer AM, Lukanov J, Sagorchev P. The influence of fulvic and ulmic acids from peat on the spontaneous contractile activity of smooth muscles. Phytomedicine 2000;7:407-415.

15. Eichehelsdörfer D. Moor in der Kurotmedizin [Moor mud in spa medicine.]: In Moor und Torfkunde, E. Stuttgart: Schweizerbart'sche Verlagsbuchhandlung, 1990.

16. Luttig G. Vorschlag zur Begriffsbestimmung für die peloide [Suggestions for the definitions of muds.]. Heilbad Kurort 1989;42:98-103.
17. Eichehelsdörfer D. Naturwissenschaftliche Charakterisierung der Peloide. [Biological characteristics of muds.]: In Kompendium der Balneologie und Kurortmedizine. Dermstadt: Steinkopff Verlag, 1989.

18. Focant M, Mignolet E, Marique M, Clabots F, Breyne T, Dalemans D, Larondelle Y. The effect of vitamin E supplementation of cow diets containing rapeseed and linseed on the prevention of milk fat oxidation. J Dairy Sci 1998;81:1095-1101.

19. Ward AT, Wittenberg KM, Przybylski R. Bovine milk fatty acid profiles produced by feeding diets containing solin, flax, and canola. J Dairy Sci 2002;85:1191-1196.

20. Khor GL. Dietary fat quality: A nutritional epidemiologist's view. Asia Pac J Clin Nutr 2004;13(Suppl.):S22.

Address reprint requests to: Ersin Odabasi, M.D. Medical Ecology and Hydroclimatology Gulhane School of Medicine Gulhane Tip Akademisi Tibbi Ekoloji ve Hidroklimatoloji $A D$.

Ankara 06018 Turkey

E-mail: ersinodabasi@hotmail.com 